\title{
The Flipped Classroom and Mind Mapping in Teaching Basic Sciences to Postgraduate Dental Students
}

\author{
Sai Sailesh Kumar Goothy ${ }^{1 *}$, Movva S1, Manyam R $^{2}$ and Reddy RS 3 \\ ${ }^{1}$ Assistant Professor \& HOD, Department of Physiology, Vishnu Dental College, India \\ ${ }^{2}$ Department of Oral Pathology, Vishnu Dental College, India \\ ${ }^{3}$ Department of Oral Medicine and Radiology, Vishnu Dental College, India
}

*Corresponding author: Dr Sai Sailesh Kumar Goothy, Assistant Professor \& HOD,

\section{Research Article \\ Volume 4 Issue 4}

Received Date: July 16, 2019

Published Date: August 16, 2019

DOI: $10.23880 / \mathrm{ijbp}-16000168$

Department of Physiology, Vishnu Dental College, Bhimavaram, Andhra Pradesh, Pin- 534202, India, Email: dr.saisailesh@gmail.com

\section{Abstract}

Context: There is a strong need to implement an effective teaching learning method to make the student to apply the knowledge that was acquired to be an efficient medical professional in the future.Hence, the current study was undertaken to observe the effectiveness of flipped class and mind mapping in teaching Basic sciences to Postgraduate Dental students.

Materials and methods: The present study was a Descriptive cross-sectional study. 36 Male $(n=14)$ and female $(n=22)$ MDS students who were willing to participate voluntarily were included in the study after obtaining the written informed consent. The topic for flipped class was blood pressure in physiology and tongue in anatomy. MCQ and mind mapping test was conducted before and after the flipped class model.One way ANOVA was used to observe significance of difference of the scores of pre and post-test. P value less than 0.05 was considered as significant. The perceptions of students were expressed as frequency and percentages.

Results: There was significant improvement in both the MCQ and mind mapping scores of physiology $(\mathrm{P}<0.01)$ and anatomy $(\mathrm{P}<0.001)$ followed by flipped classroom model. There was a highly positive feedback by the majority of students on flipped class and mind mapping.

Conclusion: As there is a gradual shift of medical education scenario from passive to active, it is the need of time to consider the latest teaching techniques which are apt for teaching the present generation students whose attention span was limited and happier to use the electronic gadgets. Both flipped class and mind mapping helps the students to apply the knowledge they have acquired and also to remember and recall the subject easily. Hence, these methods can be incorporated as a part of regular curriculum in both undergraduate and postgraduate teaching.

Keywords: Mind Mapping; Flipped Class; Higher Order Thinking Skills; Postgraduate Dental Students; Basic Sciences 


\section{International Journal of Biochemistry \& Physiology}

\section{Introduction}

In recent years, the medical education was subjected to a drastic transformation from teacher centered model to the learner centered model. In teacher centered model, that is the traditional classroom where the teacher delivers a lecture and the interaction between the teacher and student is limited. The application of the subject has to be done by the student himself as homework. In contrast, the flipped class is a learned centered model that provides more interaction between teacher and student. This is called as reverse class room because the pre study materials will be prepared and uploaded in to the software. Student can login to the software at his choice of time and download the content of his choice. He can go through the content online and off line modes and how many numbers of times he likes. Hence, these students will have a basic understanding on the topic before they come to class. This helps to convert the class into active learning sessions by introducing the problem based learning, discussion, seminar etc. All these will help to stimulate the higher order thinking skills of the students [1-4]. As the present era students are more familiar and likes to use the gadgets if the teaching also involves these gadgets, it may attract the students attention. Further, the application of the acquired knowledge was done by the student in the classroom under the guidance of the teacher. In fact, in this model, the role of the teacher will be a facilitator, who constantly observes, helps and provide feedback to students. Hence the teacher can be called as a professional educator [5,6]. Mind mapping makes mandatory to apply the knowledge what was acquired. As it makes the student to draw the understand concepts in the form of a diagram, it will be easy for them to recall the concepts. It was well known that we can remember pictures more easily than words. Though flipped class model and mind mapping have shown successful results in many countries, very few studies was there on implementation of these new technology based teaching methods in India [7]. Hence, the current study was undertaken to observe the effectiveness of flipped class and mind mapping in teaching Basic sciences to Postgraduate Dental students.

\section{Materials and Methods}

\section{Study Design and Study Population}

The present study was a Descriptive cross-sectional study. 36 Male $(n=14)$ and female $(n=22)$ MDS students who were willing to participate voluntarily were included in the study after obtaining the written informed consent. Unwilling participants were excluded from the study.

\section{Study Setting}

The present study was conducted at Department of Physiology and Department of Anatomy, Vishnu Dental College, Bhimavaram, West Godavari District, Andhra Pradesh.

\section{Structure of the Class and Evaluation}

The topic selected was Blood pressure from Physiology. A training class was conducted to MDS students to familiarize them to flipped class and mind mapping. Ten MCQ questions were related to blood pressure was prepared and given to the students to answer. The students were also asked to draw a mind map on blood pressure. This was considered as pre-test. The correct answers were given score 1 and wrong answer was given score 0 . Mind map was graded on 5 points. As there will be different type of learners like audio/visual learners, reading/writing learners and kinesthetic learners, we have prepared video, written material and case examples related to blood pressure and shared to students through whats App. All the students were asked to go through the study material before attending to the physiology class. Before starting the physiology class we have conducted a post-test with ten MCQ questions and also they were asked to draw a mind map. Then the class was conducted using problem based learning by actively interacting and involving the students. During the class all the queries by students related to topic was clarified in question and answer session. At theend of the class post-test 2 was conducted with ten MCQ questions and also they were asked to draw a mind map. Three different sets of MCQs were used for pre-test and post-test one and two. All the students were also asked to give their perceptions on flipped class and mind mapping. Data was compared to observe the effectiveness of flipped class and mind mapping. All evaluations of MCQS and mind mapping were performed by the person who is not related to the study. The same procedure was followed in anatomy and the topic selected was tongue.

\section{Ethical Consideration}

The study protocol was approved by research committee of Vishnu Dental College. As there are no ethical issues involved in the study, it was exempted from the same. 


\section{International Journal of Biochemistry \& Physiology}

\section{Statistical Analysis}

Data was analyzed by using SPSS 20.0 version. One way ANOVA was used to observe significance of difference of the scores of pre and post-test. $\mathrm{P}$ value less than 0.05 was considered as significant. The perceptions of students were expressed as frequency and percentages.

\section{Results}

Tables 1 and 2 presents the MCQ (multiple choice questions) and Mind mapping scores of the participants in physiology and anatomy, before and after flipped class. There was significant improvement in both the MCQ and mind mapping scores of physiology $(\mathrm{P}<0.01)$ and anatomy $(\mathrm{P}<0.001)$ followed by flipped classroom model. Table 3 represents the student's perception on flipped class model. There was a highly positive feedback by the majority of students on flipped class. Table 4 represents the student's perception on mind mapping. There was a highly positive feedback by the majority of students on mind mapping.

\begin{tabular}{|c|c|c|c|c|c|}
\hline Parameter & Pre-test score $(\mathbf{n = 3 6 )}$ & $\begin{array}{c}\text { Post-test 1 score } \\
(\mathbf{n = 3 6 )}\end{array}$ & $\begin{array}{c}\text { Post- test 2 score } \\
(\mathbf{n}=\mathbf{3 6})\end{array}$ & F value & P value \\
\hline MCQ & $2.41 \pm 1.02$ & $4.72 \pm 1.61$ & $5.88 \pm 0.39$ & 88.384 & $\mathrm{P}<0.01^{* * *}$ \\
\hline Mind Mapping & $1 \pm 0.41$ & $1.88 \pm 1.65$ & $2.63 \pm 1.45$ & 14.467 & $\mathrm{P}<0.01^{* * *}$ \\
\hline
\end{tabular}

Table 1: MCQ and Mind mapping scores in of the participants in physiology before and after flipped class model. (Data was presented as mean $\pm \mathrm{SD}$. ${ }^{* * *} \mathrm{P}<0.01$ is significant)

\begin{tabular}{|c|c|c|c|c|c|}
\hline Parameter & $\begin{array}{c}\text { Pre-test score } \\
(\mathbf{n = 3 6 )}\end{array}$ & $\begin{array}{c}\text { Post-test 1 score } \\
(\mathbf{n = 3 6 )}\end{array}$ & $\begin{array}{c}\text { Post- test 2 score } \\
\text { (n=36) }\end{array}$ & F value & P value \\
\hline MCQ & $2.66 \pm 0.88$ & $5.48 \pm 1.85$ & $8.54 \pm 1.27$ & 145.864 & $\mathrm{P}<0.001^{* * *}$ \\
\hline Mind Mapping & $2.09 \pm 0.63$ & $2.48 \pm 0.87$ & $3.96 \pm 0.95$ & 47.161 & $\mathrm{P}<0.001^{* * *}$ \\
\hline
\end{tabular}

Table 2: MCQ and Mind mapping scores of the participants in Anatomy before and after flipped class model. (Data was presented as mean $\pm \mathrm{SD} .{ }^{* * *} \mathrm{P}<0.001$ is significant)

\begin{tabular}{|c|c|c|c|c|c|c|}
\hline Q. No & Question & SA (\%) & A (\%) & N(\%) & D (\%) & SD (\%) \\
\hline 1 & More engaging than traditional classroom & $10(27.7)$ & $20(55.5)$ & $5(13.8)$ & $0(0)$ & $1(2.7)$ \\
\hline 2 & Liked watching lessons on video & $16(44.4)$ & $17(47.2)$ & $1(2.7)$ & $1(2.7)$ & $1(2.7)$ \\
\hline 3 & $\begin{array}{c}\text { Reading at home helped in classroom } \\
\text { performance }\end{array}$ & $16(44.4)$ & $17(47.2)$ & $2(5.5)$ & $1(2.7)$ & $0(0)$ \\
\hline 4 & Time spent on classroom was more effective & $7(19.4)$ & $24(66.6)$ & $4(11.1)$ & $1(2.77)$ & $0(0)$ \\
\hline 5 & Helped to understand the text better & $7(19.4)$ & $25(69.4)$ & $4(11.1)$ & $0(0)$ & $0(0)$ \\
\hline 6 & Quality of learning experience & $4(11.1)$ & $26(72.2)$ & $4(11.1)$ & $2(5.5)$ & $0(0)$ \\
\hline
\end{tabular}

Table 3: Students perception on flipped class model $(\mathrm{n}=36)$.

(Data was presented as frequency and percentage)

\begin{tabular}{|c|c|c|c|c|c|c|}
\hline Q. No & Questions & SA (\%) & A (\%) & N(\%) & D (\%) & SD (\%) \\
\hline 1 & Creating Mind mapping was easy & $14(38.8)$ & $19(52.7)$ & $1(2.7)$ & $1(2.7)$ & $1(2.7)$ \\
\hline 2 & Was very helpful & $15(41.6)$ & $21(58.3)$ & $0(0)$ & $0(0)$ & $0(0)$ \\
\hline 3 & Would use them again & $25(69.4)$ & $10(27.7)$ & $1(2.7)$ & $0(0)$ & $0(0)$ \\
\hline 4 & Enjoyed creating them & $22(61.1)$ & $12(33.3)$ & $1(2.7)$ & $1(2.7)$ & $0(0)$ \\
\hline 5 & Helped my recall & $28(77.7)$ & $6(16.6)$ & $1(2.7)$ & $1(2.7)$ & $0(0)$ \\
\hline
\end{tabular}

Table 4: Students perception on mind mapping.

(Data was presented as frequency and percentage) 


\section{International Journal of Biochemistry \& Physiology}

\section{Discussion}

The current study was undertaken to observe the effectiveness of flipped class and mind mapping in teaching Basic sciences to Postgraduate Dental students. There was significant in the students' performance in both MCQ and mind mapping followed by flipped class model. The combination of pre-study material and discussion in the class room was found to be more effective than the pre-study material alone. As there is advancement in the technology and majority of students were more comfortable with electronic gadgets, it is the need of time to use the technology in teaching. Slowly the momentum has started in India also which is evident with the research articles published from different medical, dental and nursing colleges [1,6-9]. These studies includes review and original articles and most of the articles has taken the perception of students and some of them conducted tests also. Majority of the studies using flipped class model has shown a improvement in the performance of the students and there was highly positive feedback from the students worldwide [10-13]. However, major limitation was lack of studies where the comparison of flipped class with other types of teaching has been made [14]. Hence, there is a need for more studies and multi centered studies comparing the flipped class model with other models. Nursing research revealed mixed results using the flipped class model [15]. Major advantage of the flipped class model is that it stimulates the higher order thinking skills of the students. It increases the interpersonal relationships. Flipped classroom shifts the class room activity from passive to active learning. As it is a learner centered teaching there will be more interaction between the teacher and student and this helps the teacher to identify the slow learners and facilitate them to understand the concepts. AJ Crothers, et al. recommended implementation of flipped class model into the dental curriculum to maximize the class room time [16]. A mind map is a simple, creative and logical way of taking notes [17]. It helps the students to present his ideas thoughts in a creative manner. Though mind mapping can be made by manual and software methods, we have used manual method in this study [18]. Earlier studies reported that there was significant improvement in learning and memory followed by the mind mapping technique [19-22]. As it was well known that it's easy to remember a picture than a word, mind maps helps the students to remember and recall the topics easily. Further it promotes the thinking of the students. In the present study there was a significant improvement in the grades of mind mapping followed by combination of the pre-study materials and the active class room time. Further, the feedback of students on mind mapping was highly positive.

\section{Conclusion}

As there is a gradual shift of medical education scenario from passive to active, it is the need of time to consider the latest teaching techniques which are apt for teaching the present generation students whose attention span was limited and happier to use the electronic gadgets. Both flipped class and mind mapping helps the students to apply the knowledge they have acquired and also to remember and recall the subject easily. Hence, these methods can be incorporated as a part of regular curriculum in both undergraduate and postgraduate teaching.

\section{Acknowledgement}

We sincerely thank Dr. MC. Suresh Sajjan, Principal and Dr. Venkata Rama Raju A, Vice-Principal, Vishnu Dental College, for their extensive support and cooperation throughout the study. Our special thanks to the management of Vishnu Dental College for providing necessary facilities for the study.

\section{References}

1. Eachempati P, Kiran Kumar KS, Abdul Rashid HJ (2018) The Flipped Classroom n dental educationlearning beyond four walls of the classroom. MedEd Publish pp: 1-19.

2. Ryback D, Sanders JJ (1980) Humanistic versus traditional teaching styles and student satisfaction. Journal of Humanistic Psychology 20(1): 87-90.

3. Alvarez B (2011) Flipping the classroom: Homework in class, lessons at home. Education Digest: Essential Readings Condensed For Quick Review 77(8): 18-21.

4. Abeysekera L, Dawson P (2015) Motivation and cognitive load in the flipped classroom: definition, rationale and a call for research. Higher Education Research \& Development 34(1): 1-14.

5. Gleason BL, Peeters MJ, Resman-Targoff BH, Samantha Karr, Sarah McBane, et al. (2011) An activelearning strategies primer for achieving ability-based educational outcomes. Am J Pharm Educ 75(9): 186. 


\section{International Journal of Biochemistry \& Physiology}

6. Srivastava K (2014) Roll of flipped classroom in education. Paripex Indian Journal of Research 3(4): 81-83.

7. Sreegiri S, Madhavi D, Kumari L (2018) Student's perception of flipped classroom teaching method in Andhra Medical College, Vishakhapatnam. IOSR Journal of Dental and Medical Sciences 17(2): 6-9.

8. Gubbiyappa KS, Barua A, Das B, Murthy VCR, Baloch HZ (2016) Effectiveness of flipped classroom with Poll Everywhere as a teaching-learning method for pharmacy students. Indian J Pharmacol 48: 41-46.

9. Presti CR (2016) The Flipped Learning Approach in Nursing Education: A Literature Review. J Nurs Educ 55(5): 252-257.

10. McLaughlin JE, Griffin LM, Esserman DA, Davidson CA, Glatt DM, et al. (2013) Pharmacy student engagement, performance, and perception in a flipped satellite classroom. Am J Pharm Educ 77(9): 196.

11. Bossaer JB, Panus P, Stewart DW, Hagemeier NE, George J (2016) Student Performance in a Pharmacotherapy Oncology Module Before and After Flipping the Classroom. Am J Pharm Educ 80(2): 31.

12. Koo CL, Demps EL, Farris C, Bowman JD, Panahi L, et al. (2016) Impact of Flipped Classroom Design on Student Performance and Perceptions in a Pharmacotherapy Course. Am J Pharm Educ 80(2): 33.

13. Morton DA, Colbert-Getz J (2016) Measuring the impact of the flipped anatomy classroom: The importance of categorizing an assessment by bloom's taxonomy. Anat Sci Educ 10(2): 170-175.

14. Chen F, Lui AM, Martinelli SM (2017) A systematic review of the effectiveness of flipped classrooms in medical education. Med Educ 51(6): 585-597.
15. Betihavas V, Bridgman $H$, Kornhaber R, Cross $M$ (2016) The evidence for 'flipping out': A systematic review of the flipped classroom in nursing education. Nurse Educ Today 38: 15-21.

16. Crothers AJ (2017) The Flipped Classroom for preclinical dental skills teaching - a reflective commentary. Br Dent J 222(9): 132.

17. Hsu LL, Chang MY, Hsieh SI (2008) Mind mapping: a new tool for enhancing student learning strategy. $\mathrm{Hu}$ Li Za Zhi 55(2): 76-80.

18. Zipp G, Maher C (2013) Prevalence of mind mapping as a teaching and learning strategy in physical therapy curricula. Journal of the Scholarship of Teaching and Learning 13(5): 21-32.

19. Muchhal M, Patthi B, Singla A, Gupta R, Malhi R, et al. (2018) Effectiveness of Mind Mapping as a Learning Tool among Dental Students. Journal of Indian Association of Public Health Dentistry 16(2): 122126.

20. Farrand P, Hussain F, Hennessy E (2002) The efficacy of the 'mind map' study technique. Med Educ 36(5): 426-431.

21. Antoni DA, Zipp GP, Olson VG, Cahill TF (2010) Does the mind map learning strategy facilitate information retrieval and critical thinking in medical students? BMC Med Educ.

22. Kalyanasundaram M, Abraham SB, Ramachandran D, Jayaseelan V, Bazroy J, et al. (2017) Effectiveness of Mind Mapping Technique in Information Retrieval Among Medical College Students in Puducherry-A Pilot Study. Indian J Community Med 42(1): 19-23. 